\title{
Synthetic nano-fibrillar extracellular matrices with predesigned macroporous architectures
}

\author{
Ruiyun Zhang, ${ }^{1}$ Peter X. $\mathbf{M a}^{1-3}$ \\ ${ }^{1}$ Department of Biologic and Materials Sciences, 1011 North University Avenue, Room 2211, The University of \\ Michigan, Ann Arbor, Michigan 48109-1078 \\ ${ }^{2}$ Department of Biomedical Engineering, The University of Michigan, Ann Arbor, Michigan 48109-1078 \\ ${ }^{3}$ Macromolecular Science and Engineering Center, The University of Michigan, Ann Arbor, Michigan 48109-1078
}

Received 27 April 2000; accepted 8 May 2000

\begin{abstract}
Scaffolding plays a pivotal role in tissue engineering. To mimic the architecture of a natural extracellular matrix component-collagen, nona-fibrous matrices have been created with synthetic biodegradable polymers in our laboratory using a phase-separation technique. To improve the cell seeding, distribution, mass transport, and new tissue organization, three-dimensional macroporous architectures are built in the nano-fibrous matrices. Water-soluble porogen materials are first fabricated into three-dimensional negative replicas of the desired macroporous architectures. Polymer solutions are then cast over the porogen assemblies in a mold, and are thermally phase-separated to form nanofibrous matrices. The porogen materials are leached out with water to finally form the synthetic nano-fibrous extracellular matrices with predesigned macroporous architectures. In
\end{abstract}

this way, synthetic polymer matrices are created with architectural features at several levels, including the anatomical shape of the matrix, macroporous elements (100 $\mu \mathrm{m}$ to millimeters), interfiber distance (microns), and the diameter of the fibers (50-500 nm). These scaffolding materials circumvent the concerns of pathogen transmission and immunorejection associated with natural collagen. With the flexibility in the design of chemical structure, molecular weight, architecture, degradation rate, and mechanical properties, these novel synthetic matrices may serve as superior scaffolding for tissue engineering. (c) 2000 John Wiley \& Sons, Inc. J Biomed Mater Res, 52, 430-438, 2000.

Key words: nano; scaffold; tissue engineering; polymer; matrix; fiber

\section{INTRODUCTION}

In the body, tissues are organized into threedimensional (3-D) structures as functional organs and organ systems. Each tissue or organ has its specific characteristic architecture depending on its biological function. This architecture is also believed to provide appropriate channels for mass transport and spatial cellular organization. Mass transport includes signaling molecules, nutritional supplies, and metabolic waste removal. Spatial cellular organization determines cell-cell and cell-matrix interactions, and is critical to the normal tissue and organ function. To engineer a tissue or organ with a specific function, a matrix material (natural or synthetic) plays a critical role in allowing for the appropriate cell distribution and in guiding the tissue regeneration in three dimensions. Therefore, to develop a scaffold for tissue engineering, the architectural design concerning the spa-

Correspondence to: P.X. Ma; e-mail: mapx@umich.edu

(c) 2000 John Wiley \& Sons, Inc. tial cellular distribution, mass transport conditions, and tissue function is very important.

A few methods have been developed to produce porous scaffolds for tissue engineering. ${ }^{1-14}$ The saltleaching technique is a popular procedure to fabricate scaffolds from biodegradable polymers. ${ }^{2,5,15}$ With this technique the pore size can be controlled by the salt particle size, and the porosity can be controlled by the salt/polymer ratio. The pore shape is, however, limited to the cubic salt crystal shape. Textile technologies have been utilized to create woven (knit) and nonwoven fibrous scaffolds for tissue engineering applications. ${ }^{4,6,9}$ The fiber diameter can be controlled at the micrometer level (typically around 15 microns), and the interfiber distance and porosity can also be manipulated in certain extent with the processing variables. However, further lowering the fiber diameter is limited with the textile technologies. To mimic the fine fibrous architecture of collagen (a natural extracellular matrix component), a novel phase separation technique has been developed in our laboratory to generate synthetic nano-fibrous extracellular matrix. ${ }^{3}$ The diameter of the fibers ranges from 50 to $500 \mathrm{~nm}$, which 
is the same as that of collagen matrix. ${ }^{16,17}$ These synthetic nano-fibrous matrices circumvent the concerns of pathogen transmission and immuno-rejection associated with collagen from animal and cadaver sources. The surface-to-volune ratio of these synthetic nanofibrous matrices is hundreds to thousands times higher than those of the nonwoven scaffolds fabricated with the textile technologies or foams fabricated with the salt-leaching techniques. ${ }^{3}$ It has been suggested that high surface-to-volume ratio enhances cell adhesion. ${ }^{3,5}$ Cell migration, proliferation, and differentiated function are also dependent on the cell adhesion for many cell types. ${ }^{18-20}$ Therefore, the nanofibrous scaffolds may serve as a better environment for cell attachment, proliferation, and function.

To improve the 3-D structure of the nano-fibrous scaffolds for cell seeding, distribution, mass transport, and tissue organization, this article reports building predesigned macroporous architectures in the nanofibrous matrices.

\section{EXPERIMENTAL}

\section{Materials}

Poly(L-lactic acid) (PLLA) with an inherent viscosity of approximately 1.6 was purchased from Boehringer Ingelheim (Ingelheim, Germany). PLLA was used without further purification. Tetrahydrofuran (THF), sugar, and $\mathrm{NaCl}$ were obtained from Aldrich Chemical (St. Louis, MO).

\section{Processing methods}

Polymer solution

PLLA was dissolved in THF to make a polymer solution with a desired concentration. It took about 2 $\mathrm{h}$ to obtain a homogeneous solution when stirred with a magnetic stirrer at $60^{\circ} \mathrm{C}$.

Preparation of geometrical porogen elements

The sugar and salt particles were sifted with standard sieves and collected by the desired sizes. The sugar fibers and thin discs were melt processed as follows. The sugar particles were contained in a beaker and heated to $120^{\circ}-130^{\circ} \mathrm{C}$ until completely melted. The sugar fibers were drawn from the sugar melt using a spatula. When one end of the spatula tip touched the sugar melt, it adhered to the melt. The spatula was slowly moved away from the melt to draw a fiber out of the melt. The fiber solidified at room temperature. The fiber diameter was controlled by the drawing rate. The fibers with diameters between 100 and $500 \mu \mathrm{m}$ were produced and separated according to the desired sizes. The sugar discs were pressed from the melt in between two glass slides. The homogeneous sugar melt was dropped on one slide and the second slide was put on top of the melt. A pressure was applied manually on the top of the slide to achieve the desired thickness. Sugar discs with a diameter of $2 \mathrm{~cm}$ and a thickness of $400 \pm 100 \mu \mathrm{m}$ were obtained for this study. The sugar discs were punched with a hot needle with a diameter of $500 \mu \mathrm{m}$ to form $\sim 50$ holes $/ \mathrm{cm}^{2}$.

Preparation of the 3-D macroporous nano-fibrous matrices

PLLA matrices with particulate macropores were prepared by combining phase-separation ${ }^{3}$ and porogen leaching techniques as follows: (A) $2.0 \mathrm{~g}$ of sugar or salt particles of desired size were added into a Teflon vial. The particle surface was leveled by tapping the vial on its upper edge and pressing with a thin plate on the top of sugar or salt. The vial was then warmed to $50^{\circ} \mathrm{C}$. Prepared PLLA/THF solution, 0.6 $\mathrm{mL}$ was pipetted and dripped slowly onto the particles. The vial containing PLLA solution and the porogen particles was then transferred into a freezer at a preset temperature to gel. (B) The vials containing the gel/particle composite were immersed into distilled water to extract the solvent and to leach the particles from the composite simultaneously for 4 days. Water was changed three times a day. (C) The gel was removed from water and blotted by a piece of filter paper, and then was kept in a freezer at $-20^{\circ} \mathrm{C}$ for at least $2 \mathrm{~h}$ to be completely frozen. (D) The frozen gel was taken into a freeze-drying vessel at between $-5^{\circ}$ and $-10^{\circ} \mathrm{C}$ in an ice/salt bath, and was freeze-dried at vaccum lower than $0.5 \mathrm{mmHg}$ for 1 week. The dried foam was then stored in a desiccator until characterization.

For the preparation of the matrix with a predesigned pore structure, the porogen components such as sugar particles, sugar fibers, and sugar discs were organized into a desired architecture. The PLLA solution was dripped into the porogen frame and then cooled down to a preset temperature to gel. After this procedure, the matrix with desired macroporous architectures were obtained with the processes (B), (C), and (D) described in the above paragraph.

In some cases, the geometrical porogen elements were stacked layer by layer to form complex pore architectures. In such a process, a moisture treatment was used for the sugar porogen components to adhere to one another. The water vapor atmosphere was pro- 
duced by putting four small dishes (Falcon, $35 \times 10$ $\mathrm{mm}$ ) of water in a big covered dish (Falcon, $150 \times 15$ $\mathrm{mm}$ ) containing the porogen assembly. The sugar porogen components had been exposed to the moisture for at least $10 \mathrm{~min}$ befor another layer was stacked.

\section{Characterization}

The melting behavior of the matrices was characterized with a differential scanning calorimeter (DSC-7, Perkin-Elmer, Norwalk, CT) as detailed previously. ${ }^{3}$ The degree of crystallinity, $X_{c}$ of a sample was calculated as: $X_{c}=\Delta H_{m} / \Delta H_{m}{ }^{0}$, where $\Delta H_{m}$ was the measured enthalpy of melting and $\Delta H_{m}{ }^{0}$ was the enthalpy of melting for $100 \%$ crystalline polymer. For PLLA, $\Delta H_{m}{ }^{0}=203.4 \mathrm{~J} / \mathrm{g}^{21}$

The estimated density and porosity of the matrix
TABLE I

Density and Porosity of PLLA Matrix Prepared from PLLA/THF Solution with Different Particulate Porogens (Gelling Temperature, $-18^{\circ} \mathrm{C}$ )

\begin{tabular}{ccccc}
\hline $\begin{array}{c}\text { PLLA/THF } \\
\begin{array}{c}\text { Concentration } \\
(\mathrm{wt} / \mathrm{v})\end{array}\end{array}$ & Porogen & $\begin{array}{c}\text { Particle } \\
\text { Size }(\mu \mathrm{m})\end{array}$ & $\begin{array}{c}\text { Density } \\
(\mathrm{g} / \mathrm{mL})\end{array}$ & $\begin{array}{c}\text { Porosity } \\
(\%)\end{array}$ \\
\hline $5.0 \%$ & Sugar & $100-250$ & 0.0272 & 97.8 \\
$5.0 \%$ & Sugar & $250-500$ & 0.0264 & 97.9 \\
$5.0 \%$ & Sugar & $500-750$ & 0.0264 & 97.9 \\
$5.0 \%$ & Salt & $100-250$ & 0.0281 & 97.8 \\
$5.0 \%$ & Salt & $250-500$ & 0.0332 & 97.4 \\
\hline
\end{tabular}

prepared from PLLA/THF were obtained as follows. A certain volume of PLLA/THF solution was pipetted into a cylindrical Teflon vial containing a porogen assembly and the matrix was fabricated as described in the Processing Methods section. The diameter and height of the matrix were measured to calculate the

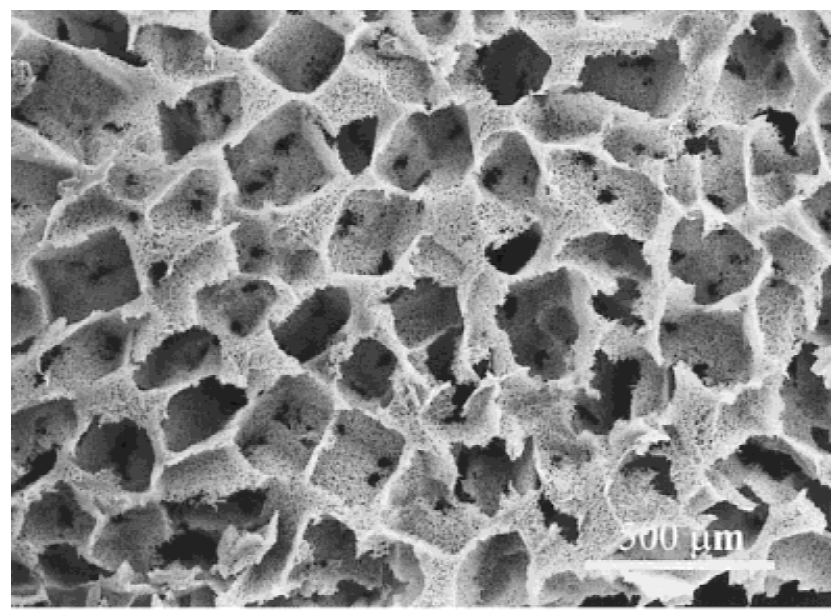

(a)

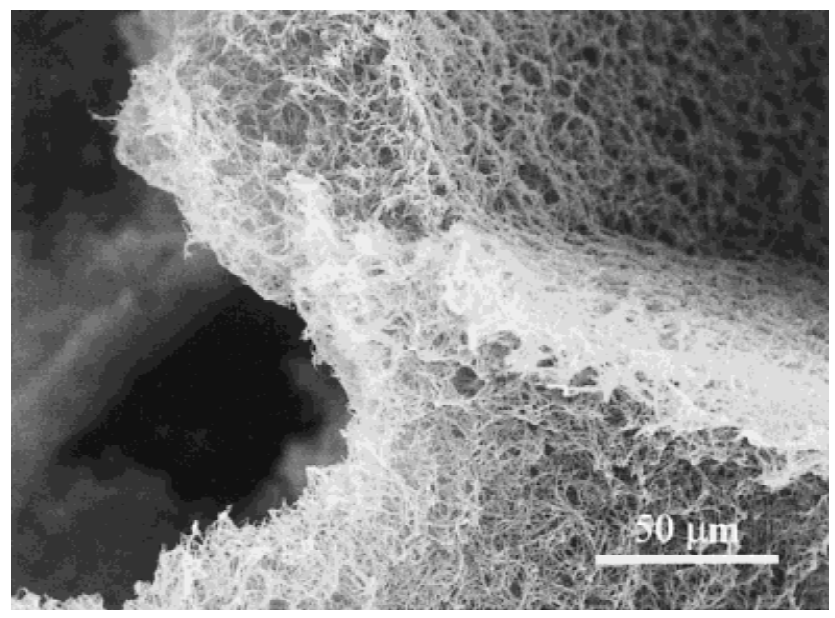

(c)

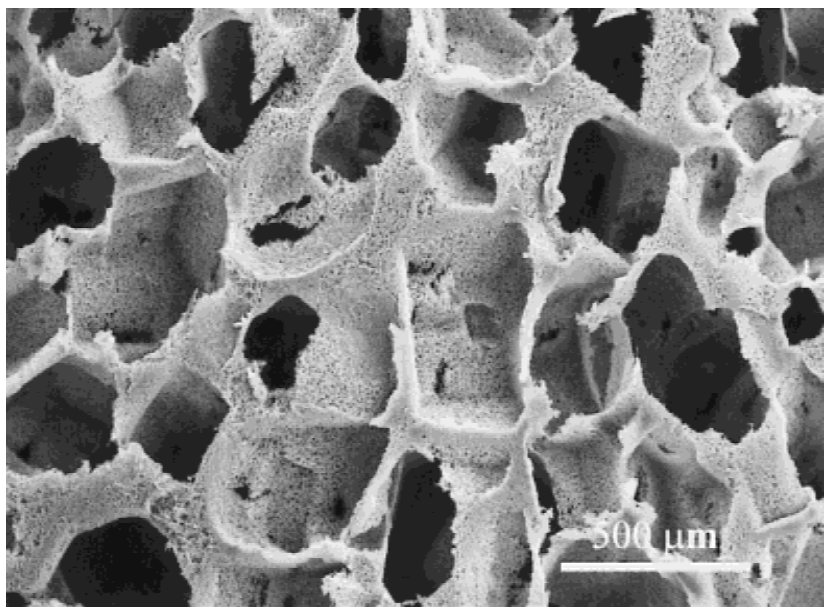

(b)

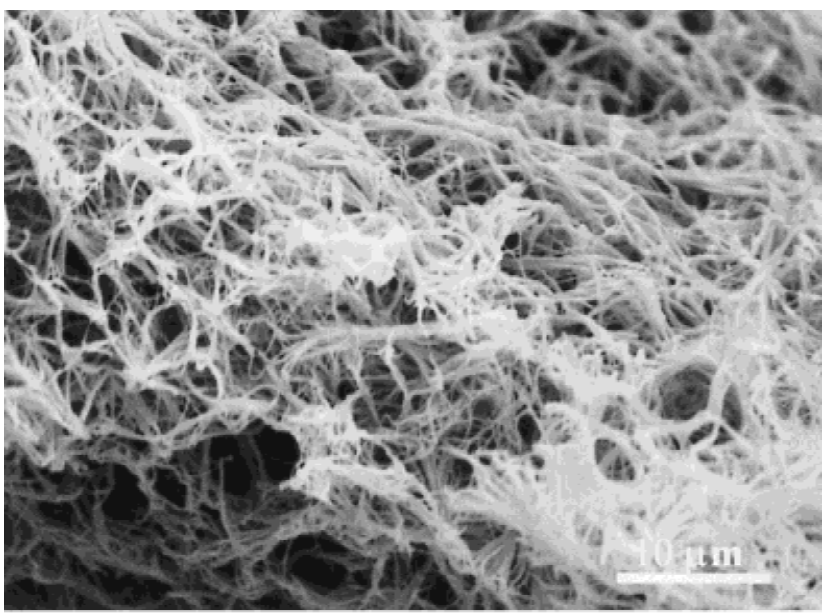

(d)

Figure 1. SEM micrographs of PLLA nano-fibrous matrix with particulate macropores prepared from PLLA/THF solution and sugar particles. (a) Particle size, 100-250 $\mu \mathrm{m}$, original magnification, $\times 50$; (b) particle size, $250-500 \mu \mathrm{m}$, original magnification, $\times 50$; (c) particle size, 250-500 $\mu \mathrm{m}$, original magnification, $\times 500$; (d) particle size, 250-500 $\mu \mathrm{m}$, original magnification, $\times 2000$. 


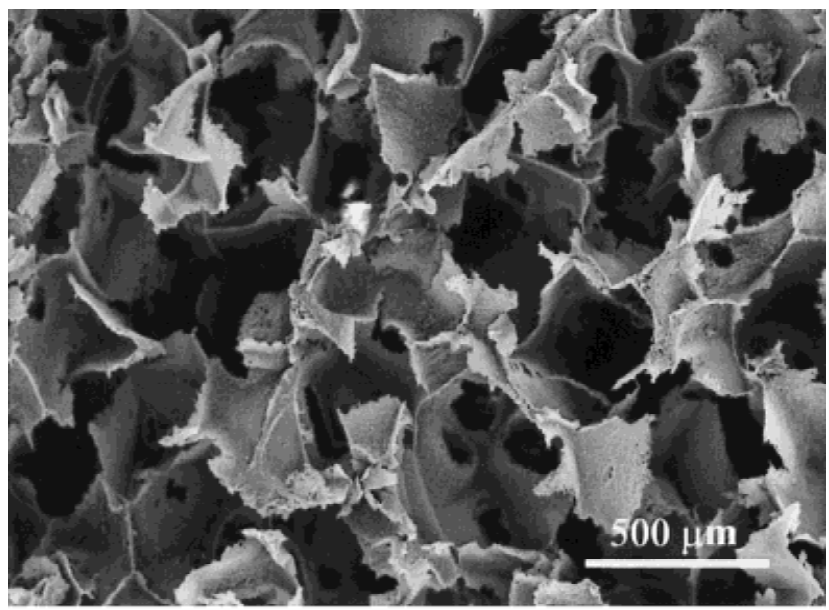

(a)

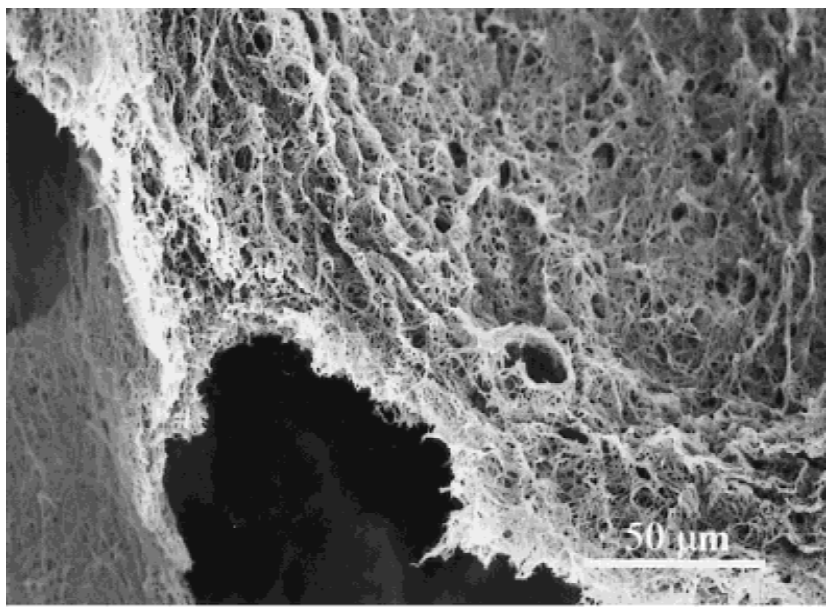

(b)

Figure 2. SEM micrographs of PLLA nano-fibrous matrix with particulate macropores prepared from PLLA/THF solution and $\mathrm{NaCl}$ particles. (a) Particle size, 250-500 $\mu \mathrm{m}$, original magnification, $\times 50$; (b) particle size, $250-500 \mu \mathrm{m}, \times 500$.

volume. The mass of the matrix was measured with an analytical balance. The density was calculated from the volume and mass. The porosity, $\varepsilon$, was calculated from the measured overall densities $D_{f}$ of the fibrous matrix and the skeletal density $D_{p}$ :

$$
\varepsilon=\frac{D_{p}-D_{f}}{D_{p}}
$$

For the fibrous matrix, the skeletal density was the density of the polymer, which was given by:

$$
D_{p}=\frac{1}{\frac{1-X_{c}}{D_{a}}+\frac{X_{c}}{D_{c}}}
$$

where $X_{c}$ was the degree of crystallinity of the polymer. The density of amorphous PLLA $\left(D_{a}\right)$ is 1.248 $\mathrm{g} / \mathrm{mL}$ and the density of $100 \%$ crystalline PLLA $\left(D_{c}\right)$ is $1.290 \mathrm{~g} / \mathrm{mL}^{22}$

The porous morphologies of the matrices were examined with scanning electron microscopy (SEM) (S$3200 \mathrm{~N}$, Hitachi, Japan) at $15 \mathrm{kV}$. To expose the internal architecture, the samples were cut with a razor blade after being frozen in liquid nitrogen for $5 \mathrm{~min}$. The samples were coated with gold using a sputter coater (Desk-II, Denton Vacuum Inc., Moorstown, NJ). The gas pressure was less than 50 mtorr and the current was approximately $40 \mathrm{~mA}$. Th coating time was $200 \mathrm{~s}$.

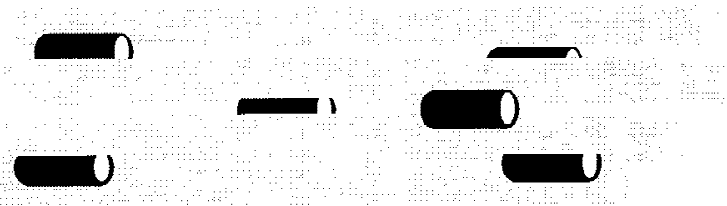

Figure 3. Schematic illustration of uniaxially oriented sugar fiber assembly.

\section{RESULTS}

\section{Particulate macroporous and nano-fibrous matrices}

Nano-fibrous matrices with particulate macropores were generated from a biodegradable polymer (PLLA) with either sugar or inorganic salt particles as a porogen in combination with a phase separation technique (Table I). These matrices have very low density and high porosity. SEM micrographs demonstrated the interconnected open pore structure and nano-fibrous pore walls (Figs. 1 and 2). There were three size scales involved in these matrices, i.e., the macropore size, interfiber distance, and fiber diameter. The macropores were a few hundred micrometers in size determined by the used porogen particle size (Fig. 1). Sugar and $\mathrm{NaCl}$ particles generated similar macropore structures for the synthetic polymer matrices (Figs. 1 and 2 ). The interfiber distance was determined by the polymer concentration used, which was similar to that of nano-fibrous PLLA matrices without sugar or salt porogen. ${ }^{3}$ The matrix morphology was also similarly determined by the phase-separation temperature, solvent used, and processing variables. The fiber diameter ranged also from 50 to $500 \mathrm{~nm}$, the same as that without the sugar or salt porogen.

\section{Uniaxially oriented tubular macroporous and nano-fibrous matrices}

Water-soluble fibers were prepared from sugar as geometrical porogen elements, and were used to form a new porous architecture, which was uniaxially oriented tubular macropores in a nano-fibrous matrix. To 


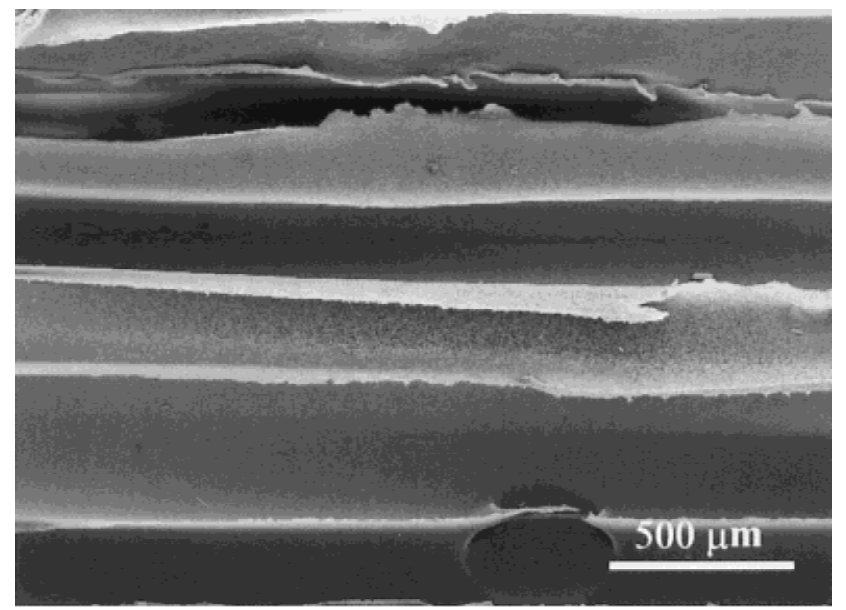

(a)

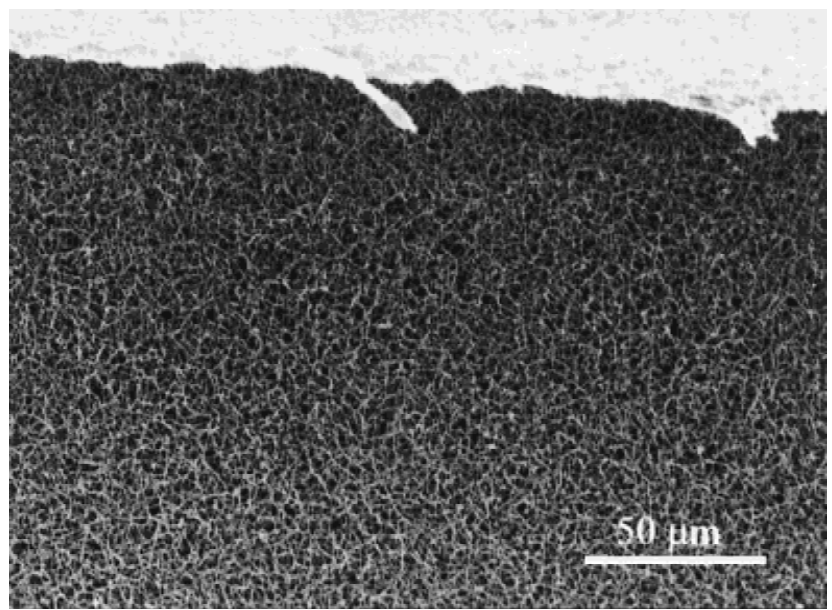

(b)

Figure 4. SEM micrographs of PLLA nano-fibrous matrix with uni-axially oriented tubular architecture prepared from PLLA/THF solution and a uniaxially oriented sugar fiber assembly. (a) original magnification, $\times 40$; (b) original magnification, $\times 500$.

obtain this complex pore architecture, the porogen frame was prepared by assembling sugar fibers in parallel (Fig. 3). The sugar fiber assembly was stablized by being exposed to a water vapor atmosphere for $1 \mathrm{~h}$, and then vacuum dried for $24 \mathrm{~h}$. The PLLA solution was dripped onto the porogen frame and cooled down to a preset temperature to gel. The composite gel then went through water leaching, freezing, and freezedrying processes as described previously. ${ }^{3}$ The SEM micrograph, taken from a central area of the sample that was cut parallel to the sugar fiber direction, demonstrated the uniaxially oriented tubular macrospore formation in a nano-fibrous matrix (Fig. 4).

\section{Orthogonal tubular macropore network and nano-fibrous matrices}

To fabricate orthogonally oriented tubular pores in a polymer matrix, the negative replica of this structure was first assembled with the porogen materialssugar fibers (Fig. 5). The sugar fibers with nearly identical diameters $(\sim 300 \mu \mathrm{m})$ were selected and parallel arranged into one layer. The second layer of the sugar fibers was laid on the top of the first layer and aligned at a right angle to the first layer. The third layer was aligned parallel to the first layer (at a right angle to the second layer). By repeating this process, an assembly of orthogonal sugar fiber plies was formed. After polymer solution casting, gelation, water leaching, and freeze-drying, a 3-D nano-fibrous matrix with orthogonal tubular macropores was obtained (Fig. 6). The SEM micrographs demonstrated that the tubular pores in different layers were interconnected at the contacting points of the original sugar fibers. A uniform diameter of sugar fibers was important to obtain open connections between the tubular macropores. A smaller sugar fiber could result in an isolated or half isolated tubular pore [Fig. 6(a)], because it might not adhere to the fibers in the neighboring layers.

\section{Helicoidal tubular macropore network and nano-fibrous matrics}

Orthogonal orientation achieved in the above section was a special case of helicoidal orientation (at a right angle between layers). Similarly, at an angle other than the right angle between layers of the sugar fibers, a helicoidal sugar fiber assembly could be obtained. An example of helicoidal fiber assembly was achieved by continuously rotating a $45^{\circ}$ angle between neighboring layers (Fig. 7). After polymer solution casting, gelation, water leaching, and freeze-drying, helicoidal tubular macropores were formed in a nanofibrous matrix (Fig. 8). The tubes were clearly interconnected into a 3-D network.

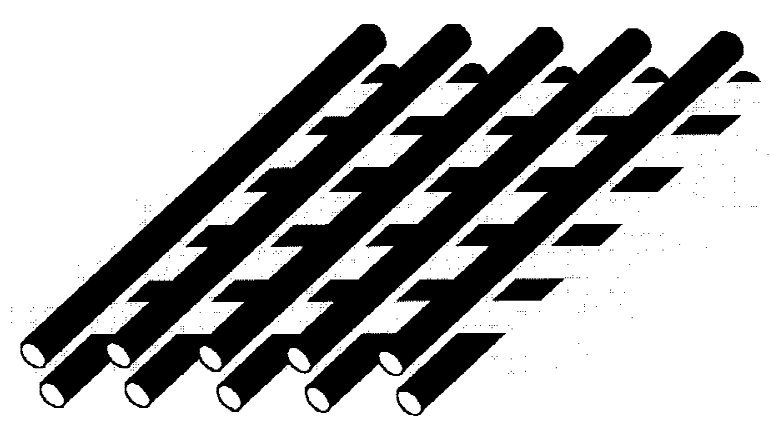

Figure 5. Schematic illustration of orthogonal sugar fiber assembly. 


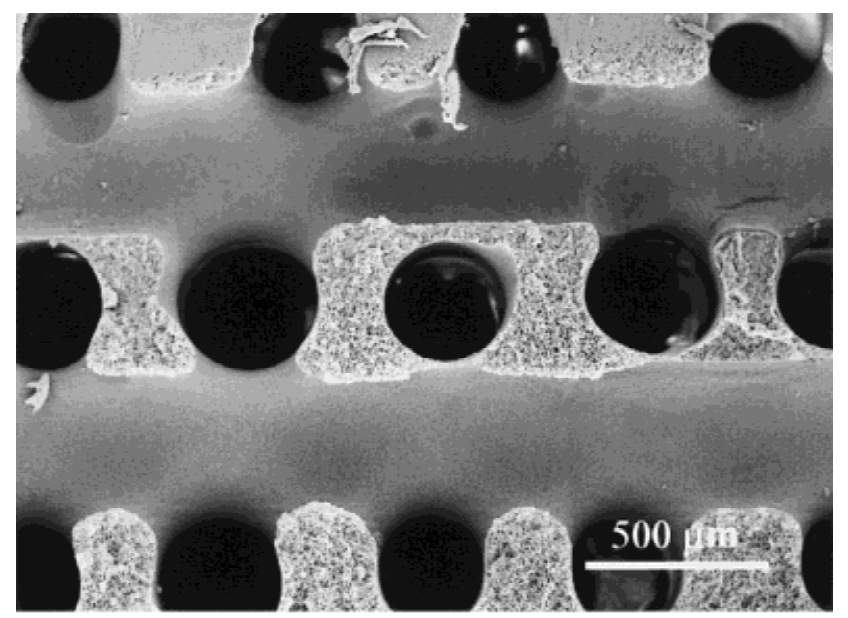

(a)

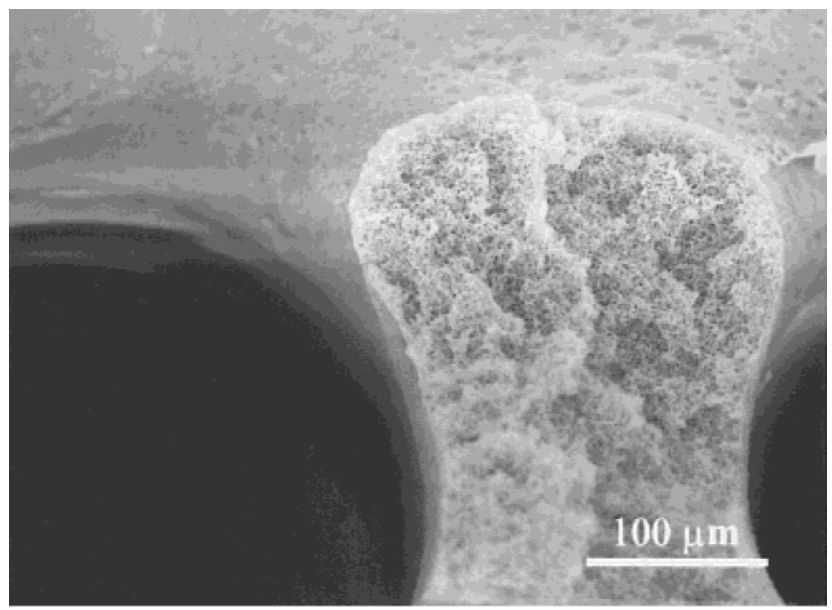

(b)

Figure 6. SEM micrographs of PLLA nano-fibrous matrix with orthogonal tubular macropore network prepared from PLLA/THF solution and an orthogonal sugar fiber assembly. (a) original magnification, $\times 40$; (b) original magnification, $\times 250$.

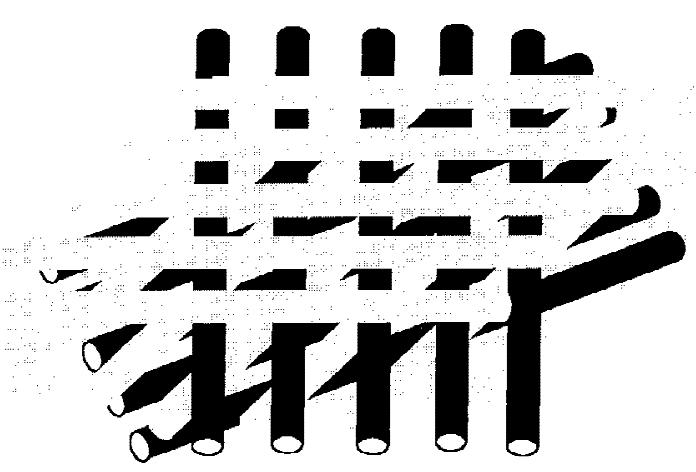

Figure 7. Schematic illustration of helicoidal sugar fiber assembly.

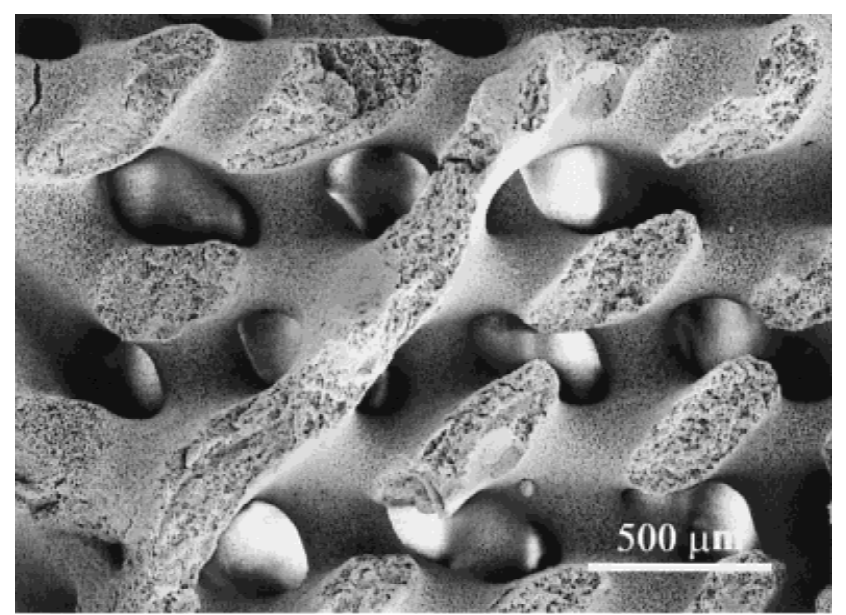

(a)

\section{Multi-layer planar macropores and nano-fibrous matrices}

Sugar discs were prepared as described in the Materials and Methods section. The sugar discs with a large number of holes were arranged together with either sugar particles or sugar fibers to form a porogen assembly (Fig. 9). After polymer solution casting, gelation, water leaching, and freeze-drying, the sugar discs became planar pores with matrix connections formed from the holes in the sugar discs (Fig. 10). The layers of sugar particles or fibers formed particulate or tubular macropores.

\section{DISCUSSION}

Tissue engineering is an interdisciplinary field that applies the principles of engineering and the life sci-

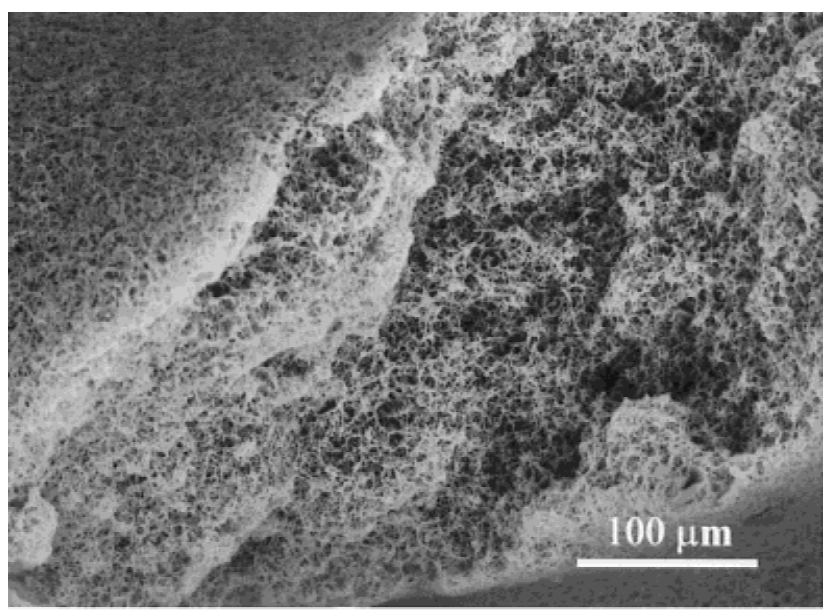

(b)

Figure 8. SEM micrographs of PLLA nano-fibrous matrix with helicoidal tubular macropore network prepared from PLLA/ THF solution and a helicoidal sugar fiber assembly. (a) original magnification, $\times 35$; (b) original magnification, $\times 250$. 

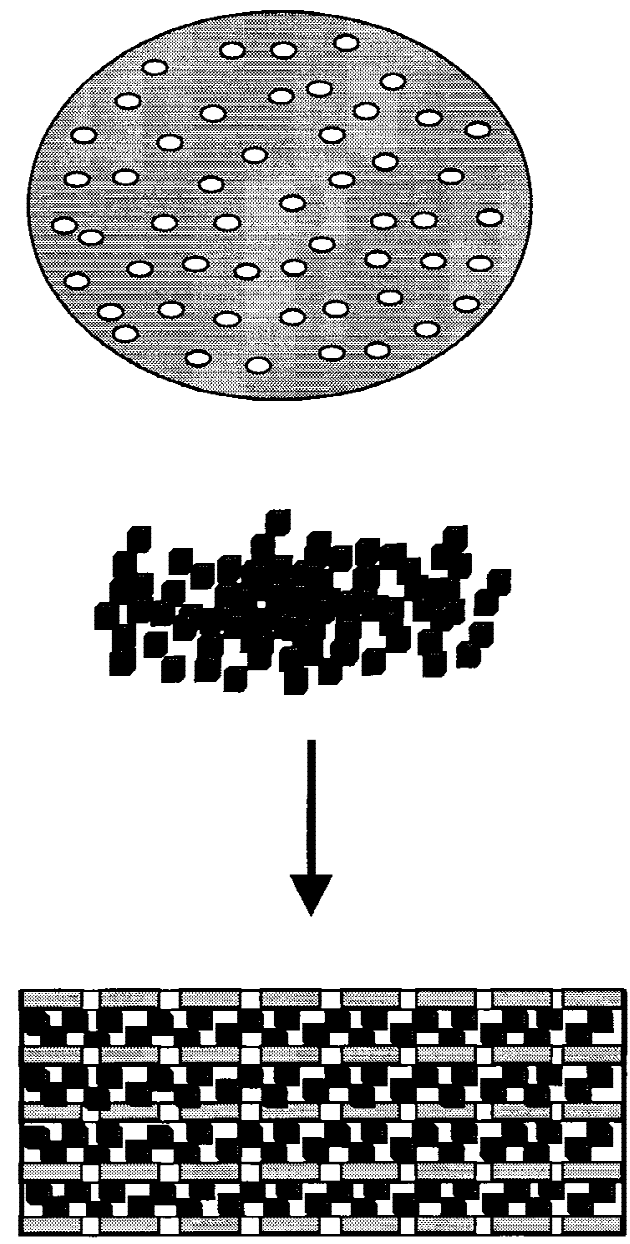

Figure 9. Schematic illustration of multi-layer sugar disc and particle assembly.

ences toward the development of biological substitutes that restore, maintain, or improve tissue function. ${ }^{23,24}$ Biomaterials play a pivotal role in tissue engineering by serving as matrices for cell seeding/ ingrowth, proliferation, and new tissue formation in three dimensions. ${ }^{3,25}$ Biodegradable polymers such as polylactide, polyglycolide, and poly(lactide-coglycolide) are biocompatible and biodegradable, ${ }^{4,5,26}$ and have been explored for a variety of tissue engineering applications. ${ }^{15,27-34}$ Collagen is a natural extracellular matrix component of many types of tissues, and its nano-fibrous architecture has long been noticed to play a role in cell adhesion, growth, and differentiated function in tissue cultures. ${ }^{16,35,36}$ To mimic the nano-fibrous architecture and overcome the concerns of disease transmission and immunogenicity associated with collagen, biodegradable polymers have been successfully processed into nano-fibrous matrices in our laboratory recently. ${ }^{3}$ In this report, we have successfully demonstrated how to create a variety of macroporous architectures in the nano-fibrous matrices, aimed to improve spatial cellular distribution, mass transfer, and new tissue organization.
We have first demonstrated how a paticulate leaching technique can be combined with a phase separation technique to generate macroporous and nanofibrous polymer matrices. In this approach, sugar and salt can be used very similarly to create macropores because both of them are soluble in water and not soluble in a selected solvent of the polymer. By utilizing the processibility of the sugar, we have further demonstrated that more complex and predesigned macroporous architectures can be created within the nano-fibrous matrices. Sugar particles, fibers, and discs have been used as examples of geometrical elements to construct the negative replicas of the macroporous architectures. We have shown that these geometrical porogen elements can be used individually or in combination to form many different macroporous architectures. We have created synthetic polymer matrices with architectural features at several levels, including the anatomical shape of the matrix, macroporous elements (ranging from $\sim 100 \mu \mathrm{m}$ to millimeters), interfiber distance (microns), and the diameter of the fibers (50-500 nm). In this way, many more geometrical shapes and size scales of sugar porogen can be produced and combined to form countless complex architectures. Although we have manually fabricated and assembled the porogen elements in this work as proof of concepts, the processes could be automated with freeform, 3-D printing, lithographic, and other micro- and even nano-fabrication technologies. These fabrication techniques are different from the traditional freeform or 3-D printing, etc. in that the initially assembled structure is the negative replica of the final pore architecture. One of the disadvantages of the freeform or 3-D printing is the structural heterogeneity due to the "pixel assembly" process. With this reversed fabrication process, the preformed is the porogen assembly that is leached out at a later stage, and a continuous nano-fibrous matrix with macroporous architecture of the negative replica of the porogen assembly is formed. This process ensures the continuity in structure and properties of the nano-fibrous matrices.

The macroporous architectural design enables cell seeding and distribution in the 3-D nano-fibrous matrices for tissue engineering. The macroporous architecture also provides channels for improved mass transport and neo-vascularization after being implanted in vivo. The cells in the macroporous nanofibrous matrices, in contrast to the foams made with traditional salt-leaching technique, will attach on and interact with a nano-fibrous network instead of "solid walls" during the in vivo and in vitro growth. These new synthetic extracellular matrices may provide better environment for cell distribution, adhesion, growth, and differentiated function. The architectural design at several size scales gives these novel matrices 


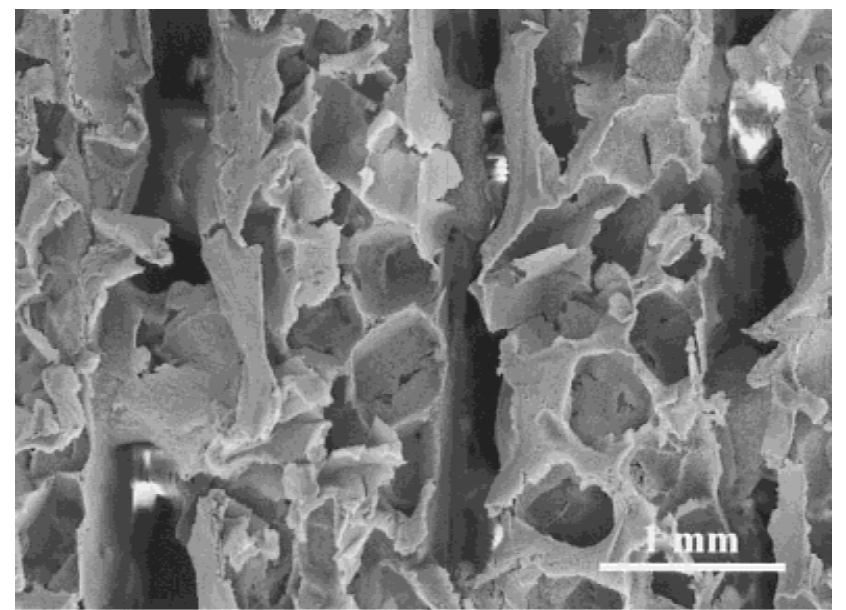

(a)

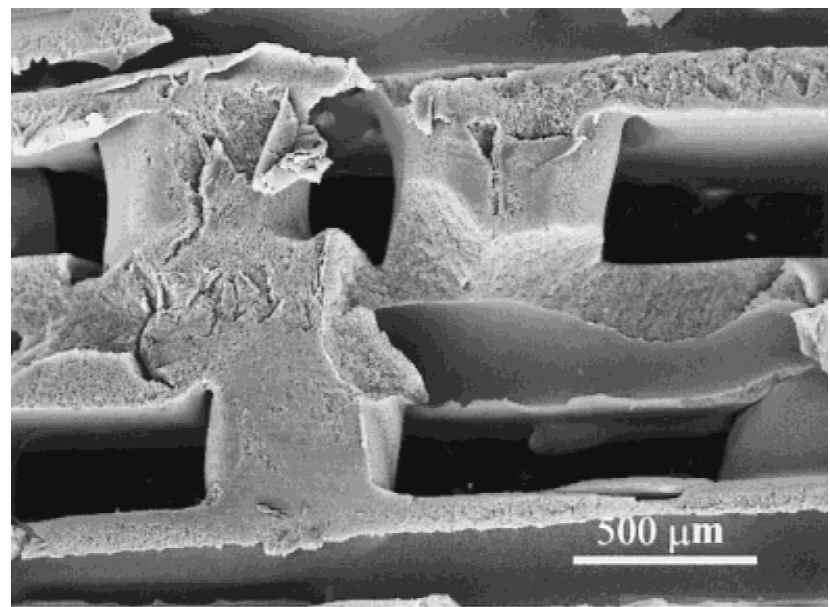

(b)

Figure 10. SEM micrographs of PLLA nano-fibrous matrix with multi-layer planar macropore network prepared from PLLA/THF solution and a 3-D assembly of sugar discs and particles (fibers). (a) From sugar discs and particles, original magnification, $\times 25$; (b) from sugar discs and fibers, $\times 30$.

the potential to be tailored into ideal scaffolds for a variety of tissue engineering applications.

\section{References}

1. Langer R. Selected advances in drug delivery and tissue engineering. J Controlled Release 1999;62(1-2):7-11.

2. Mikos AG, Thorsen AJ, Czerwonka LA, Bao Y, Langer R, Winslow DN, Vacanti JP. Preparation and characterization of poly(L-lactic acid) foams. Polymer 1994;35(5):1068-1077.

3. Ma PX, Zhang R. Synthetic nano-scale fibrous extracellular matrix. J Biomed Mater Res 1999;46(1):60-72.

4. Ma PX, Langer R. Degradatoin, structure and properties of fibrous nonwoven poly(glycolic acid) scaffolds for tissue engineering. In: Mikos AG, Leong KW, Radomsky ML, Tamada JA, Yaszemmski MJ, editors. Polymers in medicine and pharmacy. Pittsburgh: MRS; 1995. p 99-104.

5. Ma PX, Langer R. Fabrication of biodegradable polymer foams for cell transplantation and tissue engineering. In: Yarmush $\mathrm{M}$, Morgan J, editors. Tissue engineering methods and protocols. Humana Press, Inc.; Totowa, NJ: 1998.

6. Ma PX, Shin'oka T, Zhou T, Shum-Tim D, Lien J, Vacanti JP, Mayer J, Langer R. Biodegradable woven/nonwoven composite scaffolds for pulmonary artery engineering in an juvenile lamb model. Transactions of the Society for Biomaterials 1997; 20:295.

7. Lo H, Kadiyala S, Guggino SE, Leong KW. Poly(L-lactic acid) foams with cell seeding and controlled-release capacity. J Biomed Mater Res 1996;30(4):475-484.

8. Yannas IV. Applications of ECM analogs in surgery. J Cell Biochem 1994;56(2):188-191.

9. Wintermantel E, Mayer J, Blum J, Eckert KL, Luscher P, Mathey M. Tissue engineering scaffolds using superstructures. Biomaterials 1996;17(2):83-91.

10. Zhang R, Ma PX. Poly(alpha-hydroxy acids)/hydroxyapatite porous composites for bone tissue engineering. 1. Preparation and morphology. J Biomed Mater Res 1999;44(4):446-455.

11. Zhang R, Ma PX. Porous poly(L-lactic acid)/apatite composites created by biomimetic process. J Biomed Mater Res 1999;45(4): 285-293.

12. Mooney DJ, Baldwin DF, Suh NP, Vacanti JP, Langer R. Novel approach to fabricate porous sponges of poly(D,L-lactic- $\mathrm{CO}^{-}$ glycolic acid) without the use of organic solvents. Biomaterials 1996;17(14):1417-1422.

13. Athanasiou KA, Niederauer GG, Agrawal CM. Sterilization, toxicity, biocompatibility and clinical applications of polylactic acid/polyglycolic acid copolymers. Biomaterials 1996;17(2):93102.

14. Park A, Wu B, Griffith LG. Integration of surface modification and $3 \mathrm{D}$ fabrication techniques to prepare patterned poly $(\mathrm{L}-$ lactide) substrates allowing regionally selective cell adhesion. J Biomater Sci Polym Ed 1998;9(2):89-110.

15. Thomson RC, Mikos AG, Beahm E, Lemon JC, Satterfield WC, Aufdemorte TB, Miller MJ. Guided tissue fabrication from periosteum using performed biodegradable polymer scaffolds. Biomaterials 1999;20(21):2007-2018.

16. Elsdale T, Bard J. Collagen substrata for studies on cell behavior. J Cell Biol 1972;54(3):626-637.

17. Hay ED. Cell biology of extracellular matrix, 2nd ed. Plenum; New York: 1991

18. Palecek SP, Loftus JC, Ginsberg MH, Lauffenburger DA, Horwitz AF. Integrin-ligand binding properties govern cell migration speed through cell-substratum adhesiveness [published erratum appears in Nature 1997:388(6638):210] Nature 1997;385(6616):537-540.

19. Folkman J, Moscona A. Role of cell shape in growth control. Nature 1978;273(5661):345-349.

20. Benya P, Shaffer J. Dedifferentiated chondrocyts reexpress the differentiated collagen phenotype when cultured in agarose gels. Cell 1982;30(1):215-224.

21. Jamshidi K, Hyon SH, Ikada Y. Thermal characterization of polylactides. Polymer 1988;29(12):2229-2234.

22. Fischer EW, Sterzel HJ, Wegner G. Investigation of the structure of solution grown crystals of lactide copolymers by means of chemical reactions. Kolloid ZZ Polym 1973;251:980-990.

23. Langer R, Vacanti J. Tissue engineering. Science 1993; 260(5110):920-926.

24. Nerem RM, Sambanis A. Tissue engineering: From biology to biological substitutes. Tissue Eng 1995;1(1):3-13.

25. Hubbell JA. Biomaterials in tissue engineering. Biotechnology 1995;13:565-576.

26. Mikos A, Lyman M, Freed L, Langer R. Wetting of poly(L-lactic acid) and poly(DL-lactic-co-glycolic acid) foams for tissue culture. Biomaterials 1994;15(1):55-58.

27. Rodriguez A, Cao YL, Ibarra C, Pap S, Vacanti M, Eavey RD, 
Vacanti CA. Characteristics of cartilage engineered from human pediatric auricular cartilage. Plast Reconstr Surg 1999; 103(4):1111-1119.

28. Ma PX, Langer R. Morphology and mechanical function of long-term in vitro engineered cartilage. J Biomed Mater Res 1999;44(2):217-221.

29. Ma PX, Schloo B, Mooney D, Langer R. Development of biomechanical properties and morphogenesis of in vitro tissue engineered cartilage. J Biomed Mater Res 1995;29(12):1587-1595.

30. Cao Y, Vacanti J, Ma X, Paige K, Upton J, Chowanski Z, Schloo B, Langer R, Vacanti C. Generation of neo-tendon using synthetic polymers seeded with tenocytes. Transplant Proc 1994;26(6):3390-3392.

31. Freed LE, Langer R, Martin I, Pellis NR, Vunjak-Novakovic G. Tissue engineering of cartilage in space. Proceedings of the National Academy of Sciences of the United States of America 1997;94(25):13885-13890.
32. Shinoka T, Ma PX, Shum-Tim D, Breuer CK, Cusick RA, Zund G, Langer R, Vacanti JP, Mayer JE Jr. Tissue-engineered heart valves: Autologous valve leaflet replacement study in a lamb model. Circulation 1996;94(9 Suppl):II164-168.

33. Niklason LE, Gao J, Abbott WM, Hirschi KK, Houser S, Marini $\mathrm{R}$, Langer R. Functional arteries grown in vitro. Science 1999;284(5413):489-493.

34. Kim SS, Utsunomiya H, Koski JA, Wu BM, Cima MJ, Sohn J, Mukai K, Griffith LG, Vacanti JP. Survival and function of hepatocytes on a novel three-dimensional synthetic biodegradable polymer scaffold with an intrinsic network of channels. Ann Surg 1998;228(1):8-13.

35. Strom SC, Michalopoulos G. Collagen as a substrate for cell growth and differentiation. Methods in Enzymology 1982;82 Pt A:544-555.

36. Grinnell F, Bennett MH. Ultrastructural studies of cell-collagen interactions. Methods Enzymol 1982;82(Pt A):535-544. 